\title{
Variations in heart failure hospitalisation rates by socioeconomic status, Victoria, Australia
}

\author{
Timothy Ore * \\ Innovation Hub and Health System Improvement, Department of Health and Human Services, Victoria, Australia
}

Received: August 5, 2015

Accepted: September 23, $2015 \quad$ Online Published: October 15, 2015

DOI: $10.5430 /$ jer.v2n1p47

URL: http://dx.doi.org/10.5430/jer.v2n1p47

\begin{abstract}
This paper analyses variations in heart failure (HF) hospitalisation rates by community socioeconomic status (SES) in Victoria, from 1 July 2011 to 30 June 2014. The data was taken from the Victorian Admitted Episodes Dataset, the Australian Bureau of Statistics' Estimated Resident Population and Index of Relative Socioeconomic Disadvantage and the Victorian Population Health Survey. There were over 38,000 HF hospitalisations over the period. The age-standardised HF rates per 10,000 population varied inversely $(r=-0.362, p<.01)$ with SES across 79 Local Government Areas (LGA). The coefficient of variation for HF hospitalisation rates was 0.35 and 0.14 for all admissions, indicating that HF hospitalisations have a greater variation by LGA. Communities with high HF rates also had high rates of current smokers $(r=0.24)$, chronic obstructive pulmonary disease $(r$ $=0.57)$, renal failure $(r=0.54)$, diabetes $(r=0.24)$, musculoskeletal malignant neoplasms $(r=0.35)$ and Disability Support Pension recipients $(r=0.38)$. The average 30-day HF readmission rate was $25.5 \%$, the second highest of all admission categories. The HF readmission rates also varied inversely $(r=-0.38, p<.01)$ with SES. Investigating variations in HF by SES may uncover modifiable pathways. Given the high readmission rates, comorbidities and population ageing, there is a case for improving health outcomes for HF patients.
\end{abstract}

Key Words: Heart failure, Socioeconomic status, Comorbidity, Smoking, Diabetes, Renal failure, COPD

\section{INTRODUCTION}

Heart failure (HF) is an important public health issue. In the United States, HF is the leading cause of hospitalisation among adults aged 65 years and over. ${ }^{[1]}$ Approximately a quarter of HF patients are readmitted to hospital within 30 days of discharge and over half are readmitted within six months. HF patients represent about a tenth of the Medicare population in the United States but over a third of all Medicare spending. ${ }^{[1]}$ In Victoria, HF is the leading cause of death, with 7,300 people dying from the condition in 2011. The Australian Health Survey ${ }^{[2]}$ shows that a third of Victorian adults have high cholesterol and $18.3 \%$ are current smokers. In 2011-12, the Victorian Government spent $\$ 400$ million treating cardiac conditions in hospitals. The Heart Foundation $^{[3]}$ estimates that the number of Victorians living with heart disease could increase by $36 \%$ over the next decade.

Variations in HF hospital admissions have been linked to individual and community socioeconomic status (SES), based primarily on income, education and occupation. In a study of 1,383 patients (695 children and 688 adolescents) with heart disease from seven large paediatric cardiac centres in the United States, Cassedy et al. ${ }^{[4]}$ found that family income was the strongest predictor of health related quality

\footnotetext{
* Correspondence: Timothy Ore; Email: Timothy.Ore@dhhs.vic.gov.au; Address: Innovation Hub and Health System Improvement, Department of Health and Human Services, Victoria, Australia.
} 
of life for the patients. In a review, Calvillo-King et al. ${ }^{[5]}$ reported that low income and low education increased the risk for readmission among HF patients. Based on 1,372 HF hospitalisations to Parkland Memorial Hospital, Texas, Amarasingham et al. ${ }^{[6]}$ found that patients from the lowest socioeconomic quintile had higher odds of 30-day readmission to any of the 136 hospitals in the area. In a retrospective cohort study, Hu et al. ${ }^{[7]}$ found that patients living in highpoverty neighbourhoods were 28 per cent more likely than others to be readmitted within 30 days of discharge. The findings were based on data from a large (802 beds) teaching hospital in Detroit. Using data from the Telemonitoring to Improve Heart Failure Outcomes trial, Bikdeli et al. ${ }^{[8]}$ found that neighbourhood SES was significantly associated with six-month all-cause readmissions among HF patients. The study comprised 1,557 patients (524 from low SES, 516 from medium SES and 517 from high SES neighbourhoods).

Comorbidities are prevalent among HF patients. In one study (of a sample of 192,327 adults hospitalised for HF) from the United States, $82.4 \%$ had comorbidities, an average of 7.5 comorbidities per patient. Among a sample of 1,077 HF patients (54\% female) in Olmsted County, Minnesota, Dunlay et al. ${ }^{[9]}$ found that HF was the reason for hospitalisation in $16.5 \%$, other cardiovascular conditions in $21.6 \%$ and non-cardiovascular conditions in $61.9 \%$. The latter included chronic obstructive pulmonary disease (COPD), musculoskeletal conditions, renal failure, diabetes mellitus and gastrointestinal conditions. Dunlay et al. ${ }^{[9]}$ showed that the univariate predictors of HF hospitalisation included COPD, diabetes and decreased renal function. Hu et al. ${ }^{[7]}$ reported that patients hospitalised for HF with certain comorbidities had significantly higher readmission rates.

The purpose of this paper is to analyse variations in heart failure hospitalisation rates by community SES in Victoria from 1 July 2011 to 30 June 2014. It is hypothesised that patients from low SES communities have significantly higher heart failure hospitalisation rates than those from high SES communities. It is also hypothesised that communities with high heart failure hospitalisation rates have high rates of other conditions, including renal failure, diabetes, COPD and smoking.

\section{MATERIALS AND METHODS}

\subsection{The Setting}

Victoria is the second largest state in Australia, with a population of 5.8 million. Of the 79 Local Government Areas (hereafter municipality) comprising the state, 30 are in the metropolitan area and 49 are in rural and regional areas. Victoria has over 120 public and private hospitals.

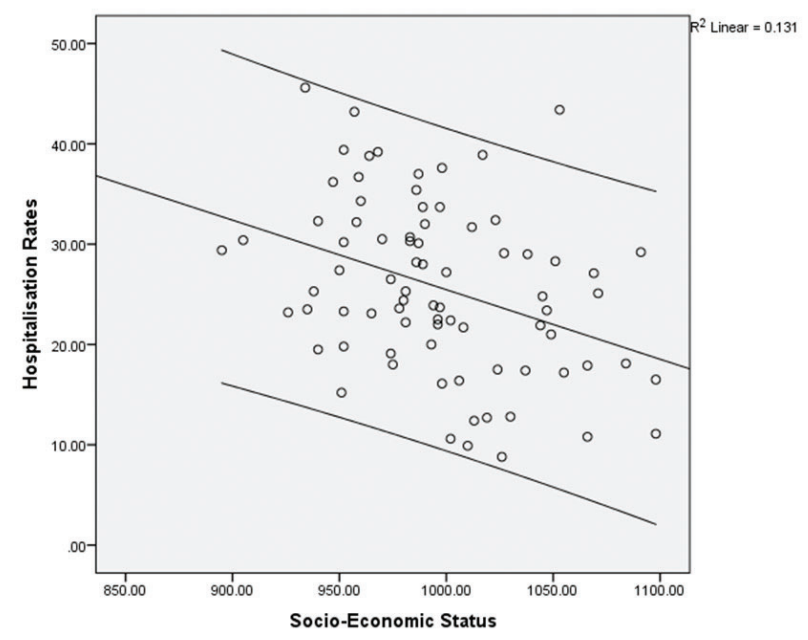

Figure 1. Association between heart failure hospitalisation rates and socioeconomic status by local government area

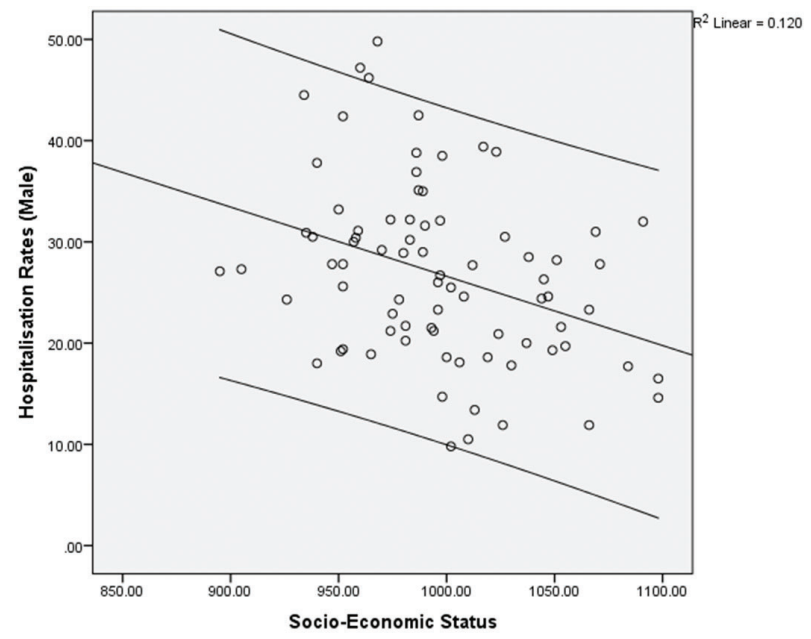

Figure 2. Association between male heart failure hospitalisation rates and socioeconomic status by local government area

\subsection{The data}

The numerator data (admissions) was from the Victorian Admitted Episodes Dataset (hereafter the dataset). Also taken from the dataset were data on COPD, renal failure and musculoskeletal malignant neoplasms.

Under the National Health Information Agreement, the National Healthcare Agreement 2011 and the Public Health and Wellbeing Act 2008, all public and private hospitals, rehabilitation centres, extended care facilities and day procedure centres must report a minimum set of data on admitted patients. The data includes admissions, separations, diagnoses and procedures. The dataset is maintained by the Department of Health and Human Services (DHHS). Hospitals submit data monthly using the Patient Reporting System, an interface and validation tool. 
Table 1. Descriptive statistics of variables

\begin{tabular}{llllll}
\hline Variable & Range & Minimum & Maximum & Mean & SEM \\
\hline Index of Relative Socioeconomic Disadvantage & 203.0 & 895 & 1098 & 996.7 & 5.022 \\
Prevalence (\%) of tobacco smoking & 14.6 & 8.60 & 23.20 & 16.1 & 0.386 \\
Prevalence (\%) of Type II diabetes & 6.30 & 2.20 & 8.50 & 4.8 & 0.149 \\
Chronic obstructive pulmonary disease hospitalisation rate per & 13.1 & 1.27 & 14.39 & 5.1 & 0.283 \\
1,000 population & & & & & \\
Prevalence (\%) of sugar-sweetened drink consumption & 22.80 & 7.50 & 30.30 & 17.1 & 0.574 \\
Engagement (\%) in mostly heavy labour and physically & 32.30 & 4.30 & 36.60 & 16.7 & 0.915 \\
demanding activity & 26.30 & 3.0 & 29.30 & 9.6 & 0.438 \\
Renal failure hospitalisation rate per 10,000 population & 8.0 & 1.40 & 9.40 & 4.4 & 0.177 \\
Percentage of population on Disability Support Pension & 19.0 & 1.4 & 20.4 & 5.5 & 0.399 \\
\hline Musculoskeletal Malignant Neoplasms per 10,000 population & & & &
\end{tabular}

Note. SEM=Standard error of mean

Table 2. Demographic profile of patients hospitalised for heart failure

\begin{tabular}{llll}
\hline & Male (\%) & Female (\%) & Total (\%) \\
\hline Age Group & & & \\
$<30$ & 47.5 & 52.5 & $80(0.2)$ \\
$31-49$ & 60.1 & 39.9 & $623(1.6)$ \\
$50-69$ & 66.0 & 34.0 & $4,950(12.8)$ \\
$70+$ & 48.7 & 51.3 & $33,161(85.4)$ \\
Co-morbidity & & & \\
With co-morbidity & 49.0 & 51.0 & $15,254(39.3)$ \\
Without co-morbidity & 51.7 & 48.3 & $23,560(60.7)$ \\
Hospital & & & \\
Public & 50.8 & 49.2 & $29,541(76.1)$ \\
Private & 51.1 & 48.9 & $9,273(23.9)$ \\
Insurance & & & \\
Hospital insurance & 51.0 & 49.0 & $12,655(32.6)$ \\
No hospital insurance & 50.9 & 49.1 & $25,447(65.6)$ \\
Insurance status unknown & 44.0 & 56.0 & $712(1.8)$ \\
Separation & & & \\
Died in hospital & 51.9 & 48.1 & $3,104(8.0)$ \\
To private residence & 51.9 & 48.1 & $25,035(64.6)$ \\
To other acute hospital/extended care & 49.0 & 51.0 & $5,783(14.9)$ \\
To aged care facility & 32.8 & 67.2 & $2,095(5.4)$ \\
Left against medical advice & 97.6 & 2.4 & $2,755(7.1)$ \\
Admission & & & \\
Emergency & 50.5 & 49.5 & $30,308(78)$ \\
Elective & 53.1 & 46.9 & $8,506(22)$ \\
\hline
\end{tabular}

The diagnosis and operation (procedure) data are coded from the patient record by qualified clinical coders using the International Classification of Diseases 10 Australian Modification/Australian Classification of Health Interventions. The dataset is not linked to other data, such as the Victorian Population Health Survey (hereafter the Health Survey) and does not contain data on patients' education, income or occupation.

Data was also taken from the 2011-12 Health Survey to examine associations of HF rates with certain health and lifestyle characteristics: prevalence of tobacco smoking (current smokers), prevalence of type 2 diabetes, prevalence of sugar sweetened drink consumption, lifetime prevalence of depression and anxiety, engagement in mostly heavy labour and physically demanding occupational activity. Conducted by the DHHS, the Health Survey is an annual survey based on computer-assisted telephone interviews of a representative sample of persons aged 18 years and over who reside in 
private dwellings. The survey uses core question modules on health and life style to inform public health policy.

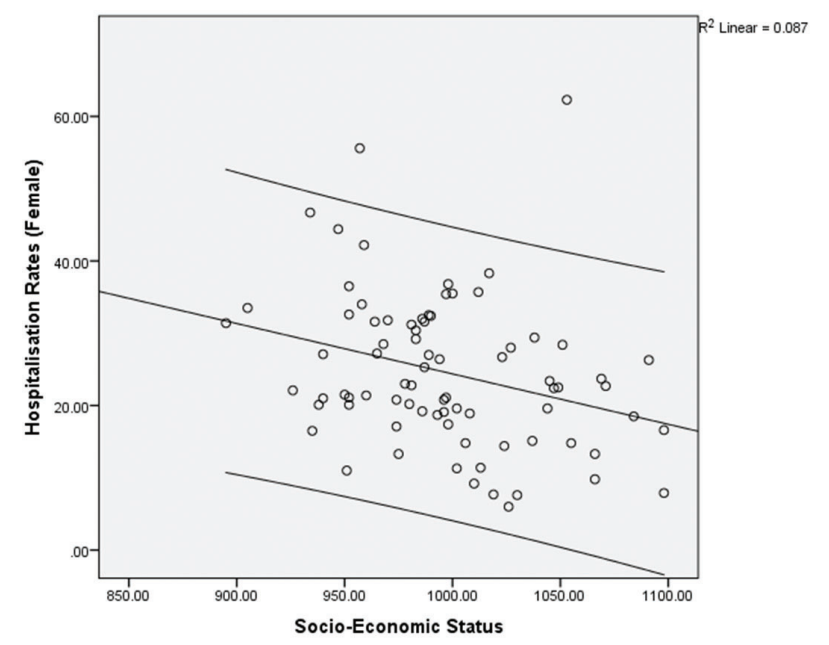

Figure 3. Association between female heart failure hospitalisation rates and socioeconomic status by local government area

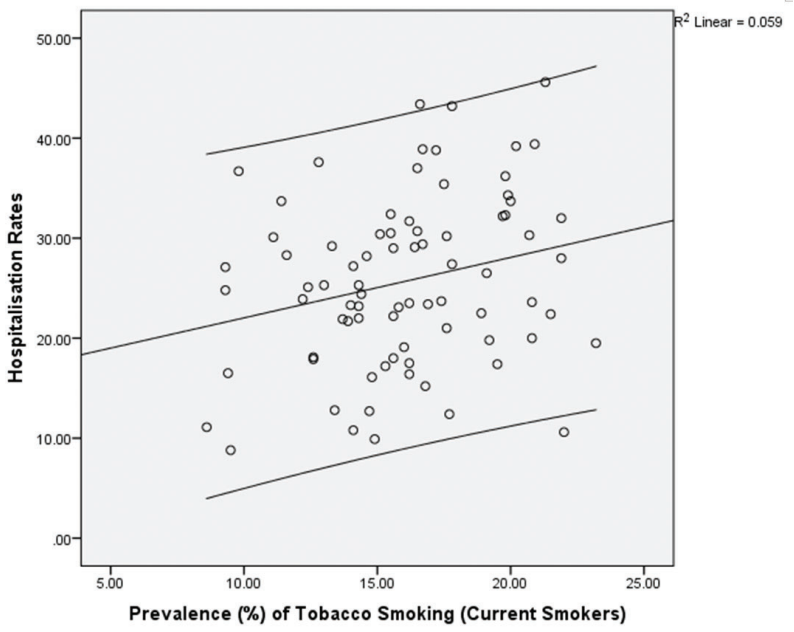

Figure 4. Association between heart failure hospitalisation rates and prevalence (\%) of tobacco smoking (current smokers) by local government area

The Health Survey sample is stratified by municipality, with a target of 426 respondents per municipality. Random digit dialling is used to generate a sample of telephone numbers. All residential households with landline telephone connections are considered "in-scope". Exclusions include people in hospitals or institutions, people who are homeless or itinerant, the frail aged and people with disabilities unable to participate in an interview.

A single respondent is randomly selected from within a household. To account for variations in household size, each respondent is treated as representing the whole household, so his or her weight factor includes a multiplier of the number of persons in the household. To ensure the probability of contacting any household is the same, the weight factor is divided by the number of telephone lines connected to the household.

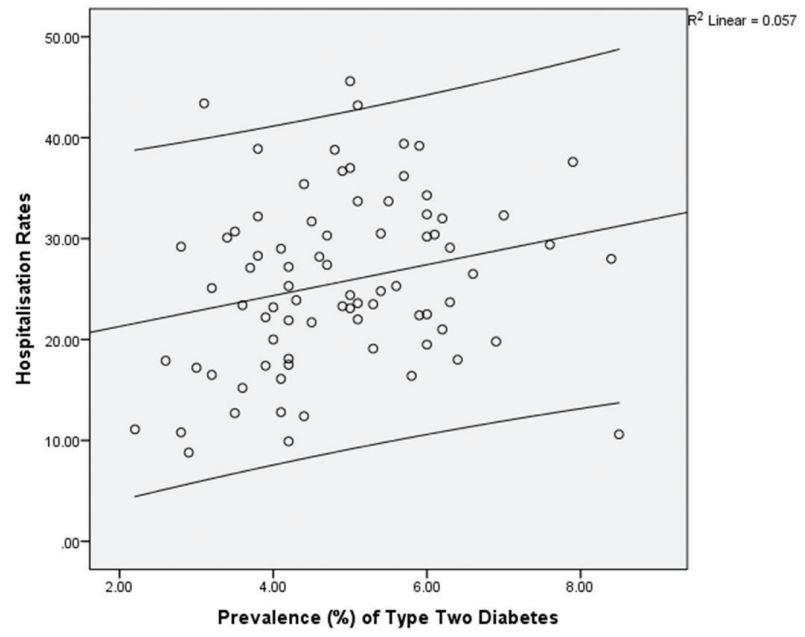

Figure 5. Association between heart failure hospitalisation rates and prevalence (\%) of type two diabetes by local government area) by local government area

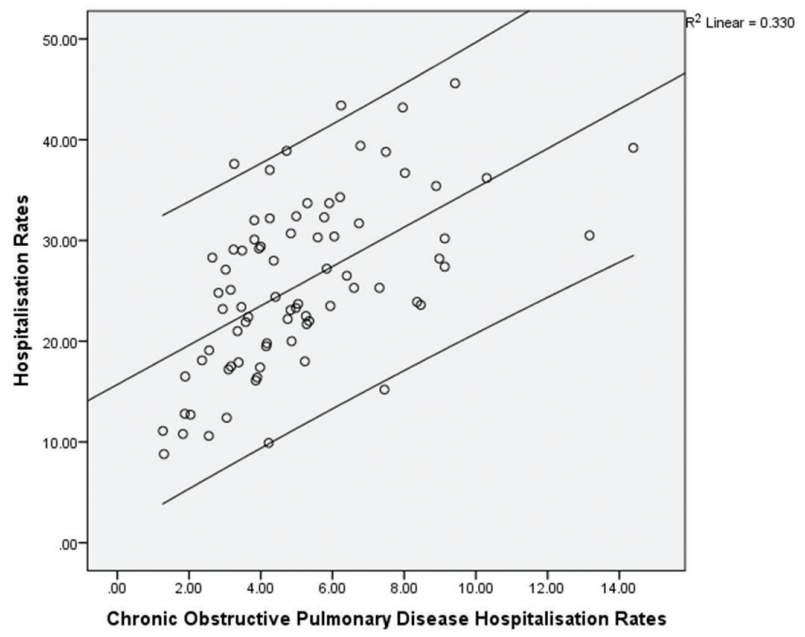

Figure 6. Association between heart failure hospitalisation rates and chronic obstructive pulmonary disease hospitalisation rates by local government area

A total of 33,673 interviews were completed for the 2011-12 Health Survey, including 800 interviews in languages other than English. Two-thirds of all completed interviews were accomplished within the first three calls. Interviews were conducted in eight community languages (Italian, Greek, Mandarin, Cantonese, Vietnamese, Arabic, Turkish and SerboCroatian). Approximately a quarter of persons living in Victoria speak languages other than English. The response rate 
ranged from $53.7 \%$ to $76.5 \%$, an average of $66.8 \%(69.9 \%$ in rural areas and $62.8 \%$ in metropolitan areas). Estimates are age-standardised to correct for differences in population age structure across municipalities.

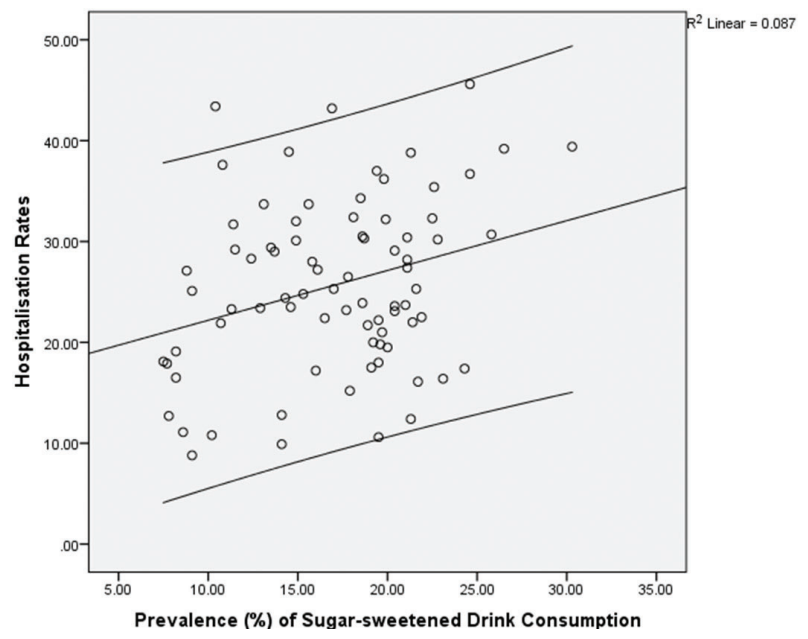

Figure 7. Association between heart failure hospitalisation rates and prevalence $(\%)$ of sugar-sweetened drink consumption by local government area

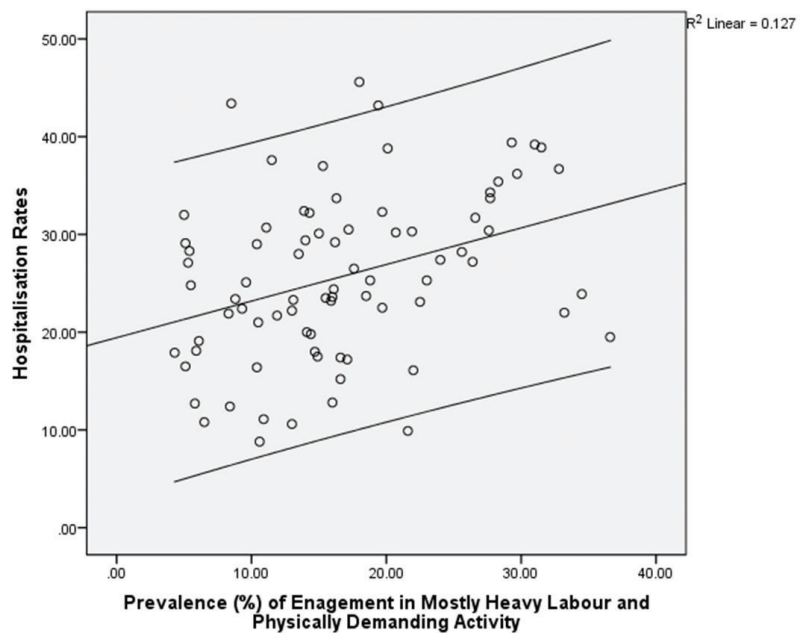

Figure 8. Association between heart failure hospitalisation rates and prevalence $(\%)$ of engagement in mostly heavy labour and physically demanding activity by local government area

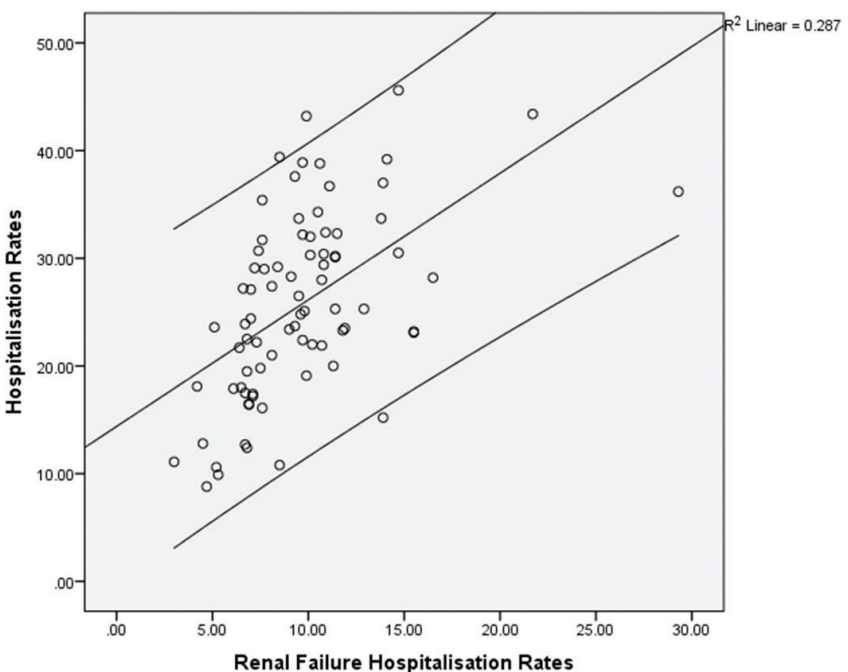

Figure 9. Association between heart failure hospitalisation rates and renal failure hospitalisation rates by local government area

Data on Disability Support Pension (DSP) (for March 2014) was from the Commonwealth Department of Human Services. There were over 200,000 persons in Victoria on DSP ( $48 \%$ female), representing approximately a quarter of the national total. The eligibility criteria for the payment include: aged between 16 years and pension age, meeting income and assets tests, unable to work for 15 hours or more a week for the next two years, permanently blind, and assessed as having a physical, intellectual or psychiatric impairment.

The denominator data (population estimates) was from the Australian Bureau of Statistics (ABS)' Estimated Resident Population (ERP). ERP is based on the most recent Census, 2011, and is derived from "place of usual residence", that is, where individuals have lived or intend to live for six months or longer in the Census year. Quarterly estimates of the population are derived by adding natural increase (births minus deaths) and net overseas migration to the estimated population at the beginning of the period. Inter-state movements involving a change of usual residence are taken into account in State estimates.

SES was measured using the ABS' Index of Relative Socioeconomic Disadvantage (IRSED) by municipality. The IRSED is a summary of multiple data on the economic and social conditions of people and households within an area. A low score suggests relatively greater disadvantage, with an area having many households on low income, many people with no qualifications or in low skilled occupations. A high score indicates a relative lack of disadvantage, in that the area has few households on low income, few people with no qualifications and few individuals in low skilled occupations. The index comprises sixteen variables, including: \% 
of people with stated household income under $\$ 20,000$ per year; \% of employed people classified as labourers; \% of families with children under 15 years of age who live with jobless parents; $\%$ of people aged 15 years and over whose highest level of education is Year 11 or lower; \% of people who do not speak English well; \% of people aged 15 years and over who have no educational attainment and \% of private dwellings with no cars. Each variable has a loading that indicates the correlation of that variable with the index. A negative loading suggests a disadvantaging variable.

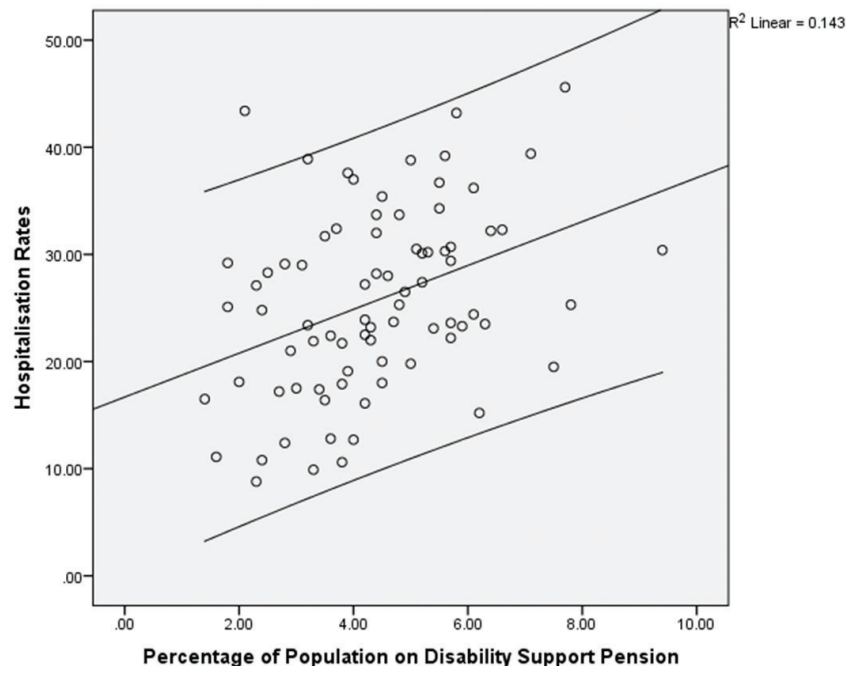

Figure 10. Association between heart failure hospitalisation rates and percentage of population on disability support pension by local government area

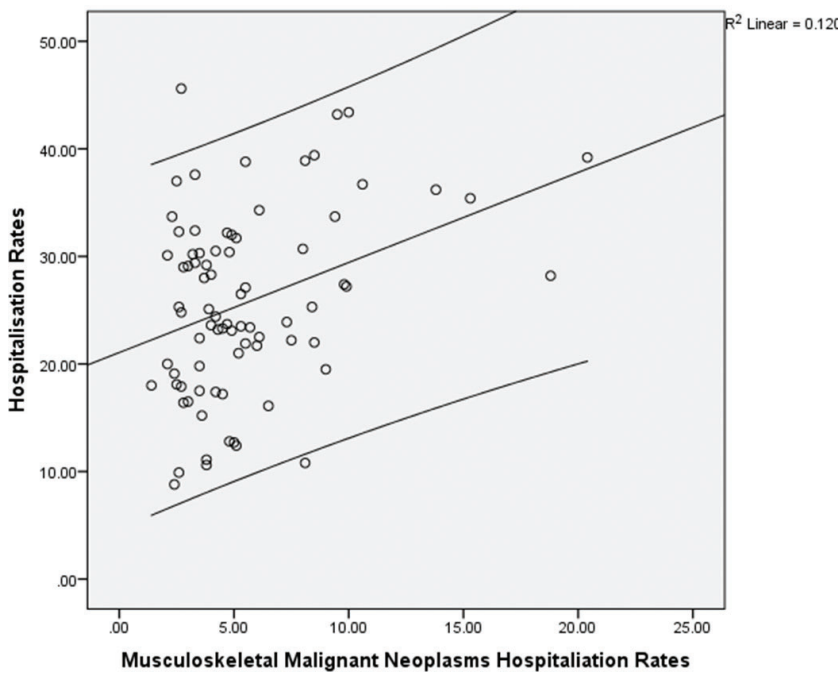

Figure 11. Association between heart failure hospitalisation rates and musculoskeletal malignant neoplasms hospitalisation rates by local government area
A summary of the data used from the Health Survey, the ABS and the Commonwealth Department of Health and Human Services is presented in Table 1. This also includes data on COPD and renal failure taken from the dataset.

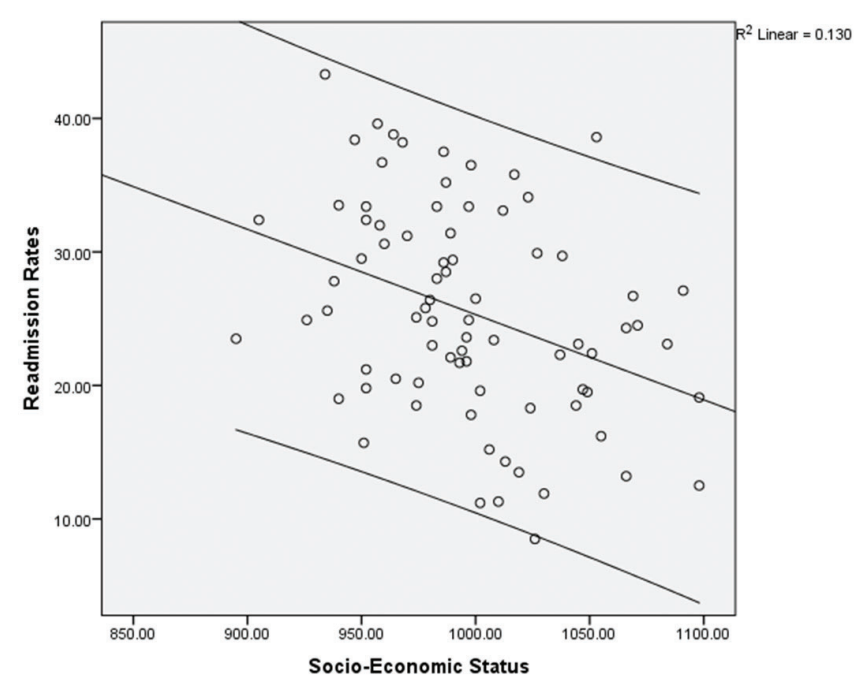

Figure 12. Association between heart failure hospital readmission rates and socioeconomic status by local government area

\subsection{Statistical analysis}

Hospitalisation rates were computed, at the municipal level, as the number of HF admissions per 10,000 population. These were age-standardised using the direct method to the 2012 Victorian population. Variations in hospitalisation rates by SES were tested using Pearson product-moment correlation coefficient, with two-tailed significance tests. A measure of degree of linear dependence between two variables, the coefficient does not indicate causality. Correlation coefficient was used because the variables in question, such as SES and hospital admission rates, are on an interval or ratio scale and in linear relation. T-test was applied to assess whether the means of relevant demographic groups were statistically different from each other. A $p$-value of $<.05$ was considered statistically significant. T-test was appropriate given the large number of cases analysed.

The coefficient of variation (CV) was computed for the HF hospitalisation rates, and compared with the distribution of the rates for all admissions by municipality. CV is calculated by dividing the standard deviation of the dataset by its mean. The distribution of all admission rates by municipality is useful for comparison to assess the relative degree of variability between conditions. Quartiles were used to describe the distribution of the $\mathrm{HF}$ admission and readmission rates by municipality, with the bottom quartile areas the lowest SES 
and the top quartile areas the highest SES. Scattergrams with linear fit and $95 \%$ confidence intervals were used to show various correlations. All statistical analyses were conducted using SPSS, version 20.

\section{RESUlts}

Over the three year period, there were $38,814 \mathrm{HF}$ admissions. The average length of stay was 9.8 days, 3.5 times that for all admission categories (2.8 days). Table 2 shows the key characteristics of the cases by gender, with statistically significant differences by age-group and separation. Men (median age $=57.5$ years) were older than women (median age $=52.1$ years). Most (98.2\%) of the patients were aged 50 years and over. Approximately $40 \%$ had catastrophic complications or comorbidities, higher among women (51\%) than men (49\%). Seventy-eight per cent of the HF admissions occurred via the Emergency Departments. Significantly more men (97.6\%) than women $(2.4 \%)$ left hospital against medical advice. Of the 3,105 (8\%) patients that died in hospitals, $62 \%$ had comorbidities.

The average admission rate was 26.7 per 10,000 population (95\% CI 25.7 - 27.6). Men had significantly $(p<.01)$ higher average rate (26.8 per 10,000 population, 95\% CI 24.8-28.7) than women (24.6 per 10,000 population, 95\% CI 22.2-26.9).

The coefficient of variation for HF admissions was 0.35 and 0.14 for all admissions. This indicates that HF hospitalisations have a greater variation by municipality than hospitalisations for all conditions.

Figures 1-3 show that the age-standardised HF hospitalisation rates varied inversely $(r=-0.362, p<.01)$ with SES, for men $(r=-0.347, p<.01)$ and women $(r=-0.295, p<.01)$. The average rate in the bottom quartile municipalities of 36.6 per 10,000 population ( $95 \% \mathrm{CI}, 33.1-39.4$ ) was 2.5 times that of the top quartile municipalities, 14.8 per 10,000 population (95\% CI, 11.7-17.2).

Table 3. Inter-correlation coefficients for heart failure admission rates and key variables

\begin{tabular}{|c|c|c|c|c|c|c|c|c|c|c|c|}
\hline & SES & HF & SMK & DIB & COP & SUG & OCA & REN & DSP & DEP & MMN \\
\hline SES & 1.00 & & & & & & & & & & \\
\hline $\mathrm{HF}$ & $-0.36 * *$ & 1.00 & & & & & & & & & \\
\hline SMK & $-0.47 * *$ & $0.24^{*}$ & 1.00 & & & & & & & & \\
\hline DIB & $-0.53 * *$ & $0.24 *$ & $0.51^{* *}$ & 1.00 & & & & & & & \\
\hline $\mathrm{COP}$ & $-0.54 * *$ & $0.57 * *$ & $0.33^{* *}$ & $0.22 *$ & 1.00 & & & & & & \\
\hline SUG & $-0.57 * *$ & $0.30 * *$ & $0.53^{* *}$ & $0.38 * *$ & $0.55^{* *}$ & 1.00 & & & & & \\
\hline OCA & $-0.51 * *$ & $0.37 * *$ & $0.27 *$ & 0.17 & $0.62 * *$ & $0.54 * *$ & 1.00 & & & & \\
\hline REN & $-0.39 * *$ & $0.54^{* *}$ & 0.21 & 0.13 & $0.51^{* *}$ & 0.17 & $0.25^{*}$ & 1.00 & & & \\
\hline DSP & $-0.89 * *$ & $0.38 * *$ & $0.46^{* *}$ & $0.41^{* *}$ & $0.55^{* *}$ & $0.57 * *$ & $0.52 * *$ & $0.32 * *$ & 1.00 & & \\
\hline DEP & -0.19 & 0.07 & $0.37 * *$ & 0.11 & 0.17 & 0.21 & 0.17 & 0.05 & $0.34 * *$ & 1.00 & \\
\hline MMN & $-0.28 *$ & $0.35^{* *}$ & 0.09 & -0.02 & $0.56^{* *}$ & $0.33^{* *}$ & $0.51 * *$ & $0.33^{* *}$ & $0.32 * *$ & 0.01 & 1.00 \\
\hline
\end{tabular}

Note. ${ }^{* *}$ Correlation is significant at the 0.01 level (2-tailed). ${ }^{*}$ Correlation is significant at the 0.05 level $(2$-tailed). SES $=$ Socioeconomic status, HF $=$ heart failure hospitalisation rates, SMK = prevalence of tobacco smoking - current smokers, DIB = prevalence of type two diabetes, COP = chronic obstructive pulmonary disease hospitalisation rates, SUG = prevalence of sugar sweetened drink consumption, OCA = engagement in occupational physical activity - mostly heavy labour and physically demanding, REN = renal failure hospitalisation rates, DSP = percentage of population on Disability Support Pension, DEP = lifetime prevalence of depression and anxiety, MMN = musculoskeletal malignant neoplasms.

Municipalities with high rates of HF hospitalisation also had high rates of other conditions (see Table 3 ). These are: tobacco smoking ( $r=0.24, p<.05$, see Figure 4$)$, Type II diabetes $(r=0.24, p<.05$, see Figure 5), age-adjusted COPD hospitalisation $(r=0.57, p<.01$, see Figure 6$)$, sugar sweetened drink consumption ( $r=0.30, p<.01$, see Figure 7 ), engagement in mostly heavy labour and physically demanding activity $(r=0.36, p<.01$, see Figure 8$)$, age-adjusted renal failure hospitalisation ( $r=0.54, p<.01$, see Figure 9), DSP recipients $(r=0.38, p<.01$, see Figure 10) and age-adjusted musculoskeletal malignant neoplasms hospitalisation (see Figure 11, $r=0.35, p<.01$ ). The correlation between lifetime prevalence of depression and anxiety and HF hospitalisation

$(r=0.07)$ was very weak.

The average 30 -day HF readmission rate was $25.5 \%$. This was the second highest of all admission categories. The HF 30-day hospital readmission rates varied inversely ( $r=$ $-0.378, p<.01$ ) with SES (see Figure 12).

\section{Discussion}

This paper has analysed variations in HF hospitalisation rates by community SES in Victoria, from 1 July 2011 to 30 June 2014. Low SES communities have significantly higher HF admission and readmission rates than high SES communities. The paper also reports strong positive correlations with several conditions, including renal failure, diabetes, COPD 
and smoking, highlighting the importance of comorbidities. Investigating variations in HF by SES is important as it may uncover modifiable risk factors. Given the high readmission rates, comorbidities and population ageing, there is a case for improving health outcomes for HF patients and reduce associated healthcare costs.

These results are consistent with those reported elsewhere. ${ }^{[4-8,10-12]}$ In Sweden, HF hospitalisation rates were $45 \%$ higher in individuals on low income than those on high income. ${ }^{[10]}$ In the First National Health and Nutrition Examination Survey in the United States, low education was associated with high HF hospitalisation. ${ }^{[12]}$ In the Uppsala Longitudinal Study, occupation and education were significant predictors of HF. ${ }^{[13]}$ In a Scottish investigation, ${ }^{[14]} \mathrm{HF}$ admission and readmission rates were greater among low SES groups than their high SES counterparts. ${ }^{[6]}$ In an analysis ${ }^{[7]}$ of 7,845 hospitalisations among Medicare fee-for-service patients, those with a history of comorbidities, such as endstage liver disease and acute renal failure, had significantly higher readmission rates than patients without these conditions. Patients living in high poverty areas had a higher risk for readmission than those living in more advantaged neighbourhoods. In a study ${ }^{[11]}$ of 18,616 patients with chronic heart failure in Copenhagen, education was significantly associated with hospitalisation. In an investigation ${ }^{[8]}$ of 1,557 heart failure patients from 33 cardiology units in the United States, patients living in low socioeconomic communities were $35 \%$ more likely to be readmitted to hospital within six months. The socioeconomic variables included income, wealth, education and occupation.

A combination of circumstances may explain why living in a low SES community, overall, results in higher heart failure hospitalisation rates. There was no available data to address such problems in this paper. However, these may include difficulties accessing primary care and community resources and post-discharge care services. ${ }^{[6]}$ As suggested by Cheung et al. ${ }^{[15]}$ and O'Brien et al. ${ }^{[16]}$ poor patients tend to use the EDs more for primary care. In Amarasingham et al.' $\mathrm{s}^{[6]}$ analysis, patients from poor neighbourhoods were more likely to be admitted through the EDs. As indicated in Table 2, over three quarters $(78 \%)$ of the heart failure hospitalisations in Victoria over the 3-year period were via the EDs.

The strength of this study lies in the identification of correlations of a range of comorbid conditions with HF hospitalisation. The prevalence of comorbidities in the patients was approximately $40 \%$ (see Table 2). While not entirely new, this highlights that improving outcomes for the patients requires active screening for comorbidities, including renal failure, COPD and diabetes. An analysis by Braunstein $e t$ $a l .{ }^{[17]}$ showed that patients with up to five or more comorbidities account for four-fifths of all hospital days by HF patients, indicating the extent of the health cost burden. In the present study, a majority of the patients who died in hospital had comorbidities.

The main limitation of the study is that it is not based on patient's information, but on aggregated data. Correlations between aggregated data could not be equivalent to those between individual data.

Another limitation is that the concept of SES does not fully capture all the elements that influence health, highlighting a need to interpret the associations presented cautiously. Factors such as differences in childhood SES, sociodemographic characteristics, and experiences of economic hardships across time, that can affect health, are not captured in standard SES measures. So are individuals' assessments of their experiences of deprivation and perceptions of their social status. Using data from the second wave (2004-05) of the English Longitudinal Study on Ageing, Demakakos et al. ${ }^{[18]}$ have shown that subjective SES is an important correlate of health in old age. As noted by Braveman et $a l,{ }^{[19]}$ in the United States, conventional occupational categories were not developed to adequately measure job-related characteristics that may influence health.

The list of fields in the Victorian Admitted Episodes Dataset does not include conventional measures of SES. With no linkage to the Victorian Population Health Survey this precluded the use of multivariate logistic regression models to quantify the effect of relevant covariates. The variations reported are based on data from an acute health setting and may not apply to the general population.

The exclusive reliance on landline telephones for the Victorian Population Health Survey means that households with only mobile phones are "out of scope". Therefore, this may represent a potential limitation on the data, in terms of representativeness, despite a high response rate $(66.8 \%)$. The proportion of households contactable via landline telephones is falling. At the end of 2012, 19\% (3.3million) of Australians aged 18 years and over were mobile phone only users, that is, have replaced their fixed line home phones with a mobile. Persons in age group 25-34 years had the highest mobile phone only usage (39\%), followed by $18-24$ years $(35 \%)$ and $35-44$ years $(15 \%)$. Mobile phone only users are more likely to be male, live in capital cities and overseas-born.

\section{Conclusion}

Significant variations by socioeconomic status exist in heart failure hospitalisations and readmissions. This represents a 
public health challenge. Addressing the range of comorbidi- care costs.

ties noted may improve health outcomes and reduce health-

\section{REFERENCES}

[1] Desai AK, Stevenson LW. Rehospitalisation for heart failure: Predict or prevent. Circulation. 2012; 126: 501-06. PMid:22825412 http: //dx.doi.org/10.1161/CIRCULATIONAHA.112.125435

[2] Australian Bureau of Statistics. Australian Health Survey: Physical Activity, 2011-12. 2013; Catalogue Number 4364.0.55.004, released 19 July.

[3] Heart Foundation. Victorian Parliamentary Inquiry into the role of community pharmacy in Victoria, Submission No. 26, 2014, Canberra.

[4] Cassedy A, Drotar D, Ittenbach R, et al. The impact of socioeconomic status on health related quality of life for children and adolescents with heart disease. Health and Quality of Life Outcomes. 2013; 11(1): 99. PMid:23777248 http://dx.doi.org/10.1186 /1477-7525-11-99

[5] Calvillo-King L, Arnold D, Eubank KJ, et al. Impact of social factors on risk of readmission or mortality in pneumonia and heart failure: systematic review. Journal of General Internal Medicine. 2013; 28(2): 269-82. PMid:23054925 http://dx.doi.org/10.1007/s 11606-012-2235- $\mathrm{x}$

[6] Amarasingham R, Moore JB, Tabak YP, et al. An automated model to identify heart failure patients at risk for 30-day readmission or death using electronic medical record data. Medical Care. 2010; 48: 98188. PMid:20940649 http://dx.doi.org/10.1097/MLR.0b013 e3181ef60d9

[7] Hu J, Gonsahn MD, Nerenz DR. Socioeconomic status and readmissions: Evidence from an urban teaching hospital. Health Affairs. 2014; 33(5): 1-8. PMid:24799574 http://dx.doi.org/10.1377 /hlthaff.2013.0816

[8] Bikdeli B, Wayda B, Bao H, et al. Place of residence and outcomes of patients with heart failure: Analysis from the Telemonitoring to Improve Heart Failure Outcomes. Journal of the American College of Cardiology. 2013; 61(10): S1-7.

[9] Dunlay SM, Redfield MM, Weston SA, et al. Hospitalisations after heart failure diagnosis. A community perspective. Journal of American College of Cardiology. 2009; 54(18): 16951702. PMid:19850209 http://dx.doi.org/10.1016/j.jacc. 2009.08.019

[10] Borne Y, Engstrom G, Essen B, et al. Country of birth and risk of hospitalisation due to heart failure: a Swedish population-based cohort study. European Journal of Epidemiology. 2011; 26: 275-83. PMid:21184142 http://dx.doi.org/10.1007/s10654-010-9 $536-3$
[11] Christensen S, Mogelvang R, Heitmann M, et al. Level of education and risk of heart failure: a prospective cohort study with echocardiography evaluation. European Heart Journal. 2011; 32: 45058. PMid:21147865 http://dx.doi.org/10.1093/eurheartj /ehq435

[12] He J, Ogden LG, Bazzano LA, et al. Risk factors for congestive heart failure in US men and women: NHANES I epidemiologic follow up study. Archives of Internal Medicine. 2001; 161: 996-1002. PMid:11295963 http://dx.doi.org/10.1001/archinte.161. 7.996

[13] Ingelsson E, Lind L, Arnlov J, et al. Socioeconomic factors as predictors of incident heart failure. Journal of Cardiac Failure. 2006; 12: 540-45. PMid:16952788 http://dx.doi.org/10.1016/j.c ardfail.2006.05.010

[14] Stewart S, Murphy NF, McMurray JJ, et al. Effect of socioeconomic deprivation on the population risk of incident heart failure hospitalisation: an analysis of the Renfrew/Paisley Study. European Journal of Heart Failure. 2006; 8: 856-63. PMid:16713336 http://dx.doi.org/10.1016/j.ejheart.2006.02.008

[15] Cheung PT, Wiler JL, Lowe RA, et al. National study of barriers to timely primary care and emergency department utilisation among Medicaid beneficiaries. Annals of Emergency Medicine. 2012; 60(1): 4-10. PMid:22418570 http://dx.doi.org/10.1016/j.annem ergmed.2012.01.035

[16] O'Brien GM, Stein MD, Zierler S, et al. Use of ED as a regular source of care: associated factors beyond lack of health insurance. Annals of Emergency Medicine. 1997; 30(3): 286-91. http://dx.doi.org/10.1016/S0196-0644(97)70163-X

[17] Braunstein JB, Anderson GF, Gerstenblith G, et al. Noncardiac comorbidity increases preventable hospitalisations and mortality among Medicare beneficiaries with chronic heart failure. Journal of the American College of Cardiology. 2003; 42: 1226-33. http: //dx.doi.org/10.1016/S0735-1097 (03) 00947-1

[18] Demakakos P, Nazroo J, Breeze E, et al. Socioeconomic status and health: the role of subjective social status. Social Science and Medicine. 2008; 67(2): 330-40. PMid:18440111 http://dx.doi . org $/ 10.1016 / j$. socscimed. 2008.03.038

[19] Braveman PA, Cubbin C, Egerter S, et al. Socioeconomic status in health research: One size does not fit all. Journal of the American Medical Association. 2005; 294(22): 2879-88. PMid:16352796 http://dx.doi.org/10.1001/jama.294.22.2879 